BARREIRO LEÓN, Bárbara (2016): “Las anticiudades posmodernas como nuevos modelos urbanos contemporáneos". Ángulo Recto. Revista de estudios sobre la ciudad como espacio plural, vol. 8, núm. 1-2, pp. 83-93. ISSN: 1989-4015.

http://dx.doi.org/10.5209/ANRE. 56721

\title{
Las anticiudades posmodernas como nuevos modelos urbanos contemporáneos
}

\author{
Bárbara BARREIRO LEÓN \\ Departamento de Historia del Arte y Musicología \\ Universidad de Oviedo \\ barbara.b.leon@gmail.com
}

Recibido: 02/02/2016

Modificado: $14 / 11 / 2016$

Aceptado: $01 / 12 / 2016$

Resumen: La cultura posmoderna nace como una corriente para combatir el Movimiento Moderno y superar la rigidez del Ilamado Estilo Internacional con respecto a la arquitectura. De esta forma, se propone no afianzar ninguna regla o razones de estilo en cuanto a la arquitectura. Esto ha traído consigo una serie de transformaciones urbanas en ciertas ocasiones caóticas y desligadas por completo de la experiencia urbana que el individuo venía teniendo hasta este momento. Se modifican el tiempo y el espacio de la ciudad para convertirla en un mero escenario de la sociedad del espectáculo.

Palabras clave: Posmodernidad, arquitectura, ciudad, urbanismo, nolugar, flâneur.

Title: The Postmodern Anti-Cities as New Urban Contemporary Models Abstract: Postmodern culture was born as a current to combat the Modern Movement and overcome the severity of the so-called International Style and its architecture. Hence, it is proponed not to enforce any rules or style reasons regarding architecture. This has brought with it a series of urban transformations disconnected from the urban experience that the individual had been having until this moment. They change the time and space of the city to become a mere stage of the society of the spectacle.

Keywords: Postmodernity, architecture, city, urbanism, non-places, flâneur.

\section{Índice}

1. Introducción

2. La anticiudad posmoderna

2.1 Coordenadas espacio-temporales en la anticiudad posmoderna

3. El flâneur posmoderno

4. Conclusiones 
BARREIRO LEÓN, Bárbara (2016): “Las anticiudades posmodernas como nuevos modelos urbanos contemporáneos". Ángulo Recto. Revista de estudios sobre la ciudad como espacio plural, vol. 8, núm. 1-2, pp. 83-93. ISSN: 1989-4015.

http://dx.doi.org/10.5209/ANRE.56721

\section{I ntroducción}

La ciudad como obra de arte debe estar sometida al estudio estético. Para poder verla de este modo, debemos tomar como ejemplos casos reales de ciudades llevadas a cabo en forma de elementos arquitectónicos. Sin embargo, para poder apreciar las ciudades posmodernas, es necesario entender los símbolos, los signos y los iconos que se nos presentan. Para entender la ciudad, debemos pensar en ella como obra de arte total que conjuga los elementos culturales de la comunidad que la integra. De esta forma, y aunque haya rasgos organizativos comunes entre unas y otras, cada ciudad tendrá una identidad propia relacionada con su historia, su paisaje y su experiencia social (Llaveria i Arasa 2008).

La Posmodernidad se presenta como un movimiento antimoderno ya que pretende escapar de todo lo que representó la Modernidad: negatividad, contradicción y contrastes (Masiero 2003). Así, la arquitectura posmoderna se presenta ante la sociedad con una voluntad de crear dos reacciones ante la masa. La primera de ellas busca coaccionar, ya que intenta decirle al individuo cómo debería vivir, o cuál sería su modo de vida apropiado. La segunda reacción es la de fomentar la irresponsabilidad del individuo, ya que le da total libertad para actuar como quiera. Sin embargo, hay momentos en que es difícil superar esta solución que plantean. Esta pluralidad hace que se pierdan los puntos de vista comunitarios, de la sociedad como conjunto, planteándose por tanto el problema de crear unos estatutos básicos y fundamentales sobre cuestiones sociales y políticas, en cuanto al sujeto y a la estética.

\section{La anticiudad posmoderna}

El término anticiudad proviene de los debates arquitectónicos que tuvieron lugar en los años 70 y que recoge en su obra Lewis Mumford (1998). Así, se utilizó este término para denominar a las zonas de suburbios de algunas ciudades de los Estados Unidos. Anticiudad se refiere a estas construcciones meramente pensadas para albergar al individuo como vivienda pero que, sin embargo, no presentaban carácter urbano. Se trataba de casas aisladas de la ciudad, a las que solo se podía acceder en el coche particular de cada familia. Aquí no existen las calles, los parques, las plazas o los lugares de ocio. Se destruye así la noción urbana de ciudad propiamente dicha, donde los individuos viven y se relacionan no solo con otros individuos, sino con el espacio urbano. En la actualidad muchos prefieren el término postciudad, no-ciudad o posturbano para referirse a la megalópolis masificada (Lins Corrêa 2009). 
BARREIRO LEÓN, Bárbara (2016): “Las anticiudades posmodernas como nuevos modelos urbanos contemporáneos". Ángulo Recto. Revista de estudios sobre la ciudad como espacio plural, vol. 8, núm. 1-2, pp. 83-93. ISSN: 1989-4015.

http://dx.doi.org/10.5209/ANRE.56721

El 15 de julio de 1972 a las 15:32 se dinamita en San Luis (Misuri) el complejo Pruitt-Igoe, ya que se consideró como un lugar inabitable debido a sus altos índices de criminalidad y marginalidad. Charles Jencks sitúa por tanto la muerte del Movimiento Moderno en ese mismo momento (Harvey 1998). A partir de este momento surgirá lo que se conoce como Posmodernidad, la cual tiende a otro tipo de arquitectura, más abierta e integrada en los centros urbanos, con un carácter totalmente nuevo.

La arquitectura posmoderna se corresponde con el conformismo de la sociedad contemporánea, ya que cuestiona la utopía arquitectónica del Estilo Internacional. Los arquitectos modernos pretendían crear un orden arquitectónico rígido dictado por la racionalidad estructural de la condición humana. De esta forma, creían que la planificación estructural del espacio llevaría a la sociedad a un comportamiento modélico (Arenas 2011). Así, tras la crisis urbana de las décadas de 1960 y 1970, casi todas las grandes ciudades sufrieron modificaciones, en ciertos casos de manera drástica, cambiando por completo algunos de sus aspectos fundamentales. Esto fue a causa del modelo socioeconómico capitalista, el cual necesita reinvertarse generacionalmente para ajustar su actividad productiva a las necesidades del mercado. Fue a mediados de la década de 1970 cuando empezamos a observar una transición hacia un nuevo tipo de ciudad: la ciudad posmoderna (Soja 2008). Esta ciudad modifica trascendentalmente su forma de vivir, de habitar, de experimentar y de comprender el espacio urbano (González Cárdenas et al. 2014).

En la cultura posmoderna, "todo vale, todo tiene interés" gracias a la pluralidad y la diversidad; pero a su vez no presenta ninguna acción legitimadora con respecto a su arquitectura (García Sánchez 2006), pues en la Posmodernidad importa más la experiencia del sujeto en el entorno urbano que el lenguaje propiamente arquitectónico.

De esta forma, el espacio y el tiempo se difuminan en cuanto hablamos del sujeto dentro de la anticiudad; se destruye la imagen preconcebida que el individuo tiene de la ciudad y se pierde entre los elementos que invitan al espectáculo, ya que no puede distinguir entre la imagen real y la manipulada (Rodríguez González 2012). Se corresponde la ciudad posmoderna, por tanto, con imaginarios urbanos, los cuales son un conglomerado de ideas e imágenes que se construyen a través de la memoria visual del individuo. A su vez, dichas creaciones imaginarias tienen que ver con el uso de la forma de la inteligencia visual-espacial. Así, estas ideas e imágenes 
BARREIRO LEÓN, Bárbara (2016): “Las anticiudades posmodernas como nuevos modelos urbanos contemporáneos". Ángulo Recto. Revista de estudios sobre la ciudad como espacio plural, vol. 8, núm. 1-2, pp. 83-93. ISSN: 1989-4015.

http://dx.doi.org/10.5209/ANRE.56721

configuran parte del universo imaginario del habitante urbano, permitiéndole interactuar con el hábitat y situándole en el tiempo, el medio físico y el espacio social (Narváez Tijerina 2011).

El individuo, por tanto, no encuentra una relación de familiaridad entre estas anticiudades y su vida diaria. Se desliga de estas nuevas construcciones desproporcionadas, sin personalidad, donde prima más la cantidad que la calidad (Lins Corrêa 2009). La arquitectura dentro de la Posmodernidad entra en el juego de los medios de comunicación de masas, donde la imagen es lo único que importa.

De esta forma, para que el individuo experimente una realidad urbana, debe existir una interacción con el espacio que le rodea. Por lo tanto, este sujeto debe también entablar una relación con respecto a la arquitectura del lugar y la configuración de la misma en la ciudad. Así, el modelo urbano presentado como asimilación o copia sistemática favorece esta interacción con el individuo (González Cárdenas et al. 2014). Este nuevo modelo de ciudad se basa en la copia, en el simulacro de la propia realidad al modo de Jean Baudrillard y sus Estrategias Fatales (1983).

\subsection{Coordenadas espacio-temporales en la anticiudad posmoderna}

El tiempo y el espacio se presentan como cuestiones elementales a la hora de elaborar un espacio urbano. Así, podríamos hablar del espacio urbano como algo temporal ya que se corresponde con la memoria, con las experiencias vividas anteriormente. Por esa misma razón, los modelos espaciales son elementos construidos por la memoria (Tudoras 2006). Sin embargo, el individuo se desconcierta ante el paisaje urbano posmoderno convirtiéndose así en un mero espectador de la ciudad. Ya no reconoce su propia ciudad debido a las modificaciones que esta ha sufrido; se rehabilitan centros urbanos deteriorados como un reclamo para el turista, son ahora ciudades ideales pero no reales, se convierten en "no-lugares", son copias de la propia ciudad. Se pierde la centralidad de las ciudades, pasando a habitar la periferia con el intento de dejar el centro casi al modo de parque temático para el turista.

La principal diferencia entre un lugar y un no-lugar es que un lugar es el conjunto de elementos que coexisten en el espacio con un cierto orden. El lugar es algo geométrico por donde los individuos caminan. Sin embargo, los elementos geográficos desaparecen cuando entran en juego los signos, ya que si los signos desaparecen, también lo hacen los rasgos geográficos que definen al lugar. De esta 
BARREIRO LEÓN, Bárbara (2016): “Las anticiudades posmodernas como nuevos modelos urbanos contemporáneos". Ángulo Recto. Revista de estudios sobre la ciudad como espacio plural, vol. 8, núm. 1-2, pp. 83-93. ISSN: 1989-4015.

http://dx.doi.org/10.5209/ANRE.56721

forma, el lugar no solo es comprendido por sus habitantes, sino por los turistas y visitantes. Estos relacionan los conceptos básicos y los elementos comunes de las ciudades mientras que en otros no consiguen establecer esa familiaridad con el espacio. Aquí podemos entender los no-lugares posmodernos debido al espacio que ocupan dentro de la ciudad contemporánea como son los aviones, trenes, automóviles, aeropuertos, estaciones, hoteles, supermercados, parques de ocio... Por tanto, los no-lugares se corresponden con los espacios ideados con fines concretos y la relación que existe entre los individuos y dichos espacios. El no-lugar no confiere identidad al individuo, al contrario, lo perturba y lo distrae, no pudiendo ubicarse en tiempo ni lugar, encontrándose solo en un espacio lleno de gente que experimenta la misma sensación (Tudoras 2006).

Perdemos una vez más la relación entre espacio y lugar que ya habíamos experimentado con el concepto de ciudad posmoderna, instalándose aquí una total atemporalidad. Existe por tanto el deseo de crear una gran ciudad, casi al modo de una "carnalidad posmoderna", ya que esta ciudad no busca resolver los problemas del individuo que la habita, no pretende ser funcional, sino que quiere crear la ilusión de una ciudad, un escenario que represente una ciudad. Los sociólogos y los arquitectos lo denominan "ciudadficción", es una nueva Disneylandia pero sacada al mundo real, falseando de forma más extraordinaria al individuo. Es una vez más la sociedad del espectáculo creando su ciudad-espectáculo (Popeanga Chelaru 2009).

Según Guy Debord en La Société du spectacle (1967), el espectáculo concentra toda la atención de esta nueva sociedad. Sin embargo, con eso no se refiere a las imágenes, sino a la relación que se establece entre los individuos y estas imágenes. Se crean imágenes que presentan una realidad, por lo que en ningún momento representarán una mentira. La finalidad del espectáculo es hacer más visibles y notables estas imágenes. Estas imágenes pueden ser admiradas en cualquier parte (Debord 1995).

Debord presenta el ejemplo de la vedette para introducir el concepto de vivencia aparente, que se encuentra en concordancia con la banalización posmoderna; una vida aparente, sin profundidad, un mundo totalmente mercantilizado donde los objetos tienden a perder valor. El individuo se encuentra cada vez más ligado al consumo, convirtiendo estos centros urbanos en espacios puramente comerciales. Este es uno de los rasgos más característicos de las ciudades posmodernas; espacios urbanos que se alejan del concepto tradicional de ciudades. Por esta razón se establece una relación 
BARREIRO LEÓN, Bárbara (2016): “Las anticiudades posmodernas como nuevos modelos urbanos contemporáneos". Ángulo Recto. Revista de estudios sobre la ciudad como espacio plural, vol. 8, núm. 1-2, pp. 83-93. ISSN: 1989-4015.

http://dx.doi.org/10.5209/ANRE.56721

directa entre la denominada anticiudad y estas ciudades posmodernas. La ciudad de Las Vegas es un ejemplo que conjuga a la perfección la ciudad/anticiudad posmoderna con la sociedad del espectáculo de Debord.

Robert Venturi, Denise Scott Brown y Steven Izenour defienden en Learning from Las Vegas (1972) construir a favor de lo que la propia sociedad reclama, de sus necesidades consumistas, en lugar de intentar construir un mundo irreal para un hombre ideal. Sugerían que los arquitectos deberían inspirarse en las formas populares y los paisajes vernáculos como son las calles comerciales y los suburbios, porque eso es lo a la gente le gusta (Ellin 1990). Esta tendencia muestra un desarrollo de la categoría arquitectónica más allá de las convenciones de la arquitectura como arte, incluyendo todo tipo de edificios que antes no estaban relacionados con el mismo (casinos, por ejemplo).

Para Venturi, todas las ciudades comunican mensajes funcionales, simbólicos y persuasivos, pero es Las Vegas, una vez más, la exageración de todos ellos, representando la arquitectura de la persuasión (Venturi et al. 2008). Será por tanto el significante y el significado de una cultura de masas llevada al extremo, y ejemplificada por una anticiudad.

En Learning from Las Vegas se afirma que la nueva ciudad posmoderna ya no debe ser juzgada por los criterios funcionalistas que habían gobernado desde el triunfo del Estilo Internacional en la década de 1930. El nuevo paisaje urbano no es ni peor ni mejor, es diferente $y$, por lo tanto, no puede ser apreciado ni juzgado con las reglas tradicionales (Hall 1995). De esta forma, el Strip de Las Vegas desborda nuestros conceptos de forma y de espacio urbano, no solo los de la antigüedad, sino también los modernos y contemporáneos al destruirlos y convertirlos en algo totalmente nuevo.

La ciudad se entiende ahora como un centro comercial, en el que todo símbolo se refiere al consumo y al ocio al modo de un parque temático. Se corresponde, en este sentido, con un espacio amnésico, efímero y dependiente de la sociedad de consumo, perdiendo su categoría de lugar como espacio antropológico. Es lo que Rem Koolhaas (2002) denomina "espacio basura" o junkspace; un espacio urbano construido a modo de conglomerado de ideas, de conceptos y lugares. Este espacio pretende complacer al individuo a través de elementos fingidos y exagerados: neones, casinos, construcciones que mezclan elementos arquitectónicos de todas las épocas con la intención de crear un estilo arquitectónico nuevo. La Posmodernidad rechaza de esta forma cualquier tipo de juicio o 
BARREIRO LEÓN, Bárbara (2016): “Las anticiudades posmodernas como nuevos modelos urbanos contemporáneos". Ángulo Recto. Revista de estudios sobre la ciudad como espacio plural, vol. 8, núm. 1-2, pp. 83-93. ISSN: 1989-4015.

http://dx.doi.org/10.5209/ANRE.56721

sentido estético a favor de una arquitectura que aboga más por lo espectacular que por lo funcional o estilístico. Es importante entender que la banalización por la cual es conocida la Posmodernidad no se ejecuta con fines arbitrarios ni debe tratarse de manera negativa, ya que transforma en objetos artísticos elementos sacados de la cultura popular, de la televisión o del cine, algo que hace que esta forma característica de arte pueda llegar a todo el mundo (Harvey 1998). El individuo se encuentra ahora en una ciudad que ya ha visto, que ya ha recorrido y a la cual ya ha viajado. Las ciudades se convierten ahora en una sola, en la misma, descontextualizando una vez más el espacio urbano.

En lo que se refiere al tiempo, el presente determinaría al sujeto, su historia y su experiencia, y por consiguiente representaría el acontecimiento en la ciudad. De esta forma, comprendemos que la ciudad se desarrolla en un espacio y un tiempo determinados, los cuales definen a la misma, dotando de identidad a los individuos que en ella se encuentran. Así, podríamos ver la ciudad como un "conjunto de hechos urbanos con significado colectivo", tal y como apunta González Cárdenas, siendo el acontecimiento el que dota de simbolismos al espacio urbano, remitiendo a la memoria colectiva e individual (González Cárdenas et al. 2014).

\section{El flâneur posmoderno}

El flâneur decimonónico de Baudelaire observaba los aspectos urbanos, las actividades ordinarias de la ciudad y sus habitantes comunes. Pretendía descubrir las profundidades de la vida urbana y de la ciudad desde un punto de vista intelectual. Escogía su camino deliberadamente dando mayor importancia a la movilidad en el espacio, al caminar, al paseo que invita a la reflexión (Durán Segura 2011).

Durante la Posmodernidad, el flâneur ha cambiado totalmente de escenario, una ciudad desconocida, cambiante, que ya nada tiene que ver con el París del siglo XIX. Se encuentra ante una ciudad dominada por la máquina y por las luces, es capaz de deambular por la anticiudad, por la no-ciudad y aun así, no sentirse del todo extraño. Este personaje se convierte en un sujeto cualquiera de la ciudad posmoderna y contemporánea, se convierte en un elemento más de la ciudad, en artista, arquitecto y obra de la misma.

Flânerie es el paseo, el vagar sin rumbo por la ciudad; una práctica propicia en la ciudad posmoderna y contemporánea donde el movimiento es una constante básica para el ritmo de vida actual. De esta forma, nos es posible conocer y observar el devenir de los 
BARREIRO LEÓN, Bárbara (2016): “Las anticiudades posmodernas como nuevos modelos urbanos contemporáneos". Ángulo Recto. Revista de estudios sobre la ciudad como espacio plural, vol. 8, núm. 1-2, pp. 83-93. ISSN: 1989-4015.

http://dx.doi.org/10.5209/ANRE.56721

individuos y la masa social como elementos en tránsito continuo. En este momento, el flâneur desempeña un papel de crítico en cuanto a la "estética urbana y al capitalismo moderno" (Durán Segura 2011).

El flâneur original frecuentaba las calles, plazas, parques, callejuelas, y otros espacios contruidos para el ocio como cines o teatros. Se interesó especialmente por los pasajes del siglo XIX, hasta desarrollar un gusto por las calles comerciales. Uno de los principales atractivos de estos lugares era observar los escaparates, ya que representaban el reflejo de la sociedad que paseaba por estos lugares. Esto enlaza con el tratamiento del flâneur contemporáneo y su gusto por los centros comerciales y de ocio. Surge así una nueva forma de flânerie; la de observar la ciudad desde el interior, desde las ventanas o terrazas como un voyeur (Curdavic García 2012). Así, la nueva interioridad de la ciudad se ejemplifica a través de los lugares de ocio, ya que los individuos caminan por el centro comercial sin ningún sentido más que el de analizar y observar lo que allí se les presenta; locales, tiendas, cafeterías, o gente transitando de un lugar a otro sin rumbo. De esta forma, estos lugares se convierten en las nuevas ciudades, entramados urbanos bajo techo con el objetivo de albergar a la masa y facilitar su actividad.

Ramallo Guzmán (2014) habla incluso de un tecnoflâneur cuyos pasos han sido completamente tomados por la tecnología. Realiza sus visiones del espacio urbano a través de la red, donde hace todo lo que cualquier individuo podría realizar en una ciudad física: pasear, comprar, jugar e incluso interaccionar con el entorno. El tecnoflâneur representa la evolución y el futuro del individuo en la ciudad, no ya solo como experto y crítico de la misma, sino también como sujeto e individuo que habita y vive la ciudad. El elemento urbano se va disipando a favor de una realidad aumentada que nos permite vivir al exterior desde cualquier elemento electrónico de nuestro hogar. La ciudad se convierte entonces en un elemento más de la vivienda, existiendo dentro de ella y utilizándola a nuestro antojo.

\section{Conclusiones}

La Posmodernidad pretendió desde sus inicios crear una nueva expresión no solo artística, sino también cultural, lo que a su vez traerá consigo una nueva experiencia estética cambiante y contradictoria que busca representar la sociedad contemporánea. Se generará ahora una nueva arquitectura como reflejo de una sociedad totalmente renovada, liberada de los presupuestos estéticos, filosóficos y sociales de mediados del siglo XX. 
Se crea, por tanto, un nuevo tipo de ciudad, donde los signos y los símbolos juegan un papel fundamental a la hora de entender el significado de la ciudad. Son espacios con edificios planos y sin alma, dotados de un carácter nuevo sin recurrir a elementos propiamente arquitectónicos, sino llenos de signos que representan nuestra sociedad. Estos signos pueden incluso servir para dar a un objeto vacío categoría artística y estética; un cartel con luces de neón es el punto más álgido de la sociedad posmoderna.

Así pues, relacionamos las ciudades posmodernas con la existencia de las anticiudades, un espacio en el que no existen las categorías urbanas básicas para poder denominarlo "ciudad". Los habitantes de las mismas vivirán recluidos en el exterior, mientras que la propia ciudad será ahora un mero escenario para el turista, para los ojos del visitante posmoderno. Estas nuevas ciudades están plagadas de no-lugares en los que el sujeto se pierde, no encuentra su rumbo, ya que no representan la experiencia de su espacio urbano porque se han modificado a favor de la nueva cultura posmoderna. El individuo es ahora un mero espectador y comienza a indagar al modo del flâneur para no perderse en el tiempo ni en el espacio posmoderno.

La Posmodernidad es una cultura irónica, una parodia cínica de la sociedad, a la que pretende criticar imitando sus modelos pero representados a su vez con una fuerte personalidad, no solo en términos individuales, sino remitiéndose a la historia y al cambio de las sociedades.

\section{Bibliografía}

ARENAS, Luis (2011): Fantasmas de la vida moderna. Ampliaciones y quiebras del sujeto en la ciudad contemporánea. Madrid: Trotta.

AUGÉ, Marc (1993): Los no-lugares: Espacios del anonimato. Una antropología de la sobremodernidad. Barcelona: Gedisa.

CURDAVIC GARCÍA, Dorde (2012): El flâneur en las prácticas culturales, el costrumbrismo y el modernismo. París: Éditions Publibook Université.

DEBORD, Guy (1995): La sociedad del espectáculo. Madrid: Ediciones Naufragio.

DURÁN SEGURA, Luis Armando (2011): “Miradas urbanas sobre el espacio público: el flâneur, la deriva y la etnografía de lo urbano". Reflexiones, vol. 90, núm. 2, pp. 137-144. 
ELLIN, Nan (1990): Postmodern Urbanism. Nueva York: Princeton Architectural Press.

GARCÍA SÁNCHEZ, Rafael (2006): Una revisión de la “Deconstrucción Postmoderna" en Arquitectura. Tesis Doctoral. Valencia: Departamento de Composición Arquitectónica de la Escuela Técnica Superior de Arquitectura de la Universidad Politécnica de Valencia.

GIL ORIVE, Maria (2013): “¿Habitar la ciudad? Una aproximación a la experiencia de lo urbano desde la práctica". Arte y Ciudad: Revista de Investigación, núm. 3, vol. I Extraordinario, pp. 385402.

GONZÁLEZ CÁRDENAS, María; SALAZAR FERRO, Camilo; y URREA UYABÁN, Tatiana (2014): "Re-correr la ciudad". URBS: Revista de Estudios Urbanos y Ciencias Sociales, vol. 4, núm. 1, pp. $139-157$.

HALL, Peter (1995): Cities of Tomorrow. Oxford: Blackwell.

HARVEY, David (1998): La condición de la posmodernidad: Investigación sobre los orígenes del cambio cultural. Buenos Aires: Amorrortu.

KOOLHAAS, Rem (2002): “J unkspace”. October, núm. 100, pp. 175190.

LINS CORRÊA, Elyane (2009): “Urbanizaciones temáticas: arquitecturas del deseo". Perspectivas urbanas, núm. 10, pp. 13-22.

LLAVERIA i ARASA, Joan (2008): "El arte de construir ciudad", en Diálogos urbanos. Confluencias entre arte y ciudad. I Congreso Internacional Arte y Entorno. Celebrado en Valencia el 13, 14 y 15 de diciembre de 2006, pp. 7-12. Valencia: Universidad Politécnica de Valencia.

MASIERO, Roberto (2003): Estética de la arquitectura. Madrid: La Balsa de la Medusa.

MUMFORD, Lewis (1998): A cidade na Historia. São Paulo: Martins Fontes.

NARVÁEZ TIJERINA, Adolfo Benito (2011): “El imaginario urbano eurocéntrico y la anticiudad utópica de Wright". Revista contexto, pp. 65-80.

POPEANGA CHELARU, Eugenia (2009): “Modelos urbanos: de la ciudad moderna a la ciudad posmoderna". Ángulo Recto. Revista de estudios sobre la ciudad como espacio plural, núm. 0.

RAMALLO GUZMÁN, Francisco Jesús (2014): El espacio real, sugerido o soñado, como categoría surrealista en la producción artística 
contemporánea. Tesis Doctoral. Granada: Universidad de Granada.

RODRÍGUEZ GONZÁLEZ, Javier (2012): “Las categorías de espacio y tiempo en el marco teórico de la Posmodernidad". Ensayos: Revista de la Facultad de Educación de Albacete, núm. 27.

SOJA, Edward (2008): Postmetrópolis: Estudios críticos sobre la ciudad y las regiones. Madrid: Traficantes de Sueños.

TUDORAS, Laura Eugenia (2006): "Propuesta para una lectura postmoderna de la ciudad". Cuadernos de Filología Italiana, vol. 13, pp. 129-141.

VENTURI, Robert; SCOTT BROWN, Denise; e IZENOUR, Steven (2008): L'einsegnement de Las Vegas. Bruselas: Mardaga. 